\title{
Characterization and Properties of Boriding Titanium Alloy Ti6Al4V
}

\author{
A. KAOUKA ${ }^{a, *}$ AND K. Benarous ${ }^{b}$ \\ ${ }^{a}$ Ecole Normale Supérieure de Laghouat, Laghouat, Algeria \\ ${ }^{b}$ Laboratoire de Sciences Fondamentales, Laghouat University, Laghouat, Algeria
}

\begin{abstract}
The main objective of this work is to study the boriding treatment of titanium alloy Ti6Al4V and its characterisation. Boriding treatment was performed in solid medium based of boron carbide $\mathrm{B}_{4} \mathrm{C}$, at 900,950 , and $1050{ }^{\circ} \mathrm{C}$ for 2,4 , and $6 \mathrm{~h}$. Scanning electron microscopy, optical microscopy, and X-ray diffraction were used to characterize boride layers formed on titanium alloy Ti6Al4V. The microstructure of boride layers obtained on the surface of titanium alloy and some mechanical properties such as microhardnesses of borides layers formed were investigated.
\end{abstract}

DOI: 10.12693/APhysPolA.137.493

PACS/topics: boriding, titanium alloy, characterization, microhardness

\section{Introduction}

Boronizing or boriding is defined as a thermochemical surface treatment process of diffusion and chemical reaction of boron atoms into the substrate at elevated temperatures ranging between 800 to $1000^{\circ} \mathrm{C}$ for several hours [1-3]. Thus, boron atoms are diffused into a metal substrate and form one or more hard boride layers on the metal surface. Boriding procedure is dependent on boriding agent, boriding type, boriding temperature, and boriding time. Boriding temperature is the biggest factor, which affects the cost of the process and choice of the substance to be borided. Elevated temperatures may be detrimental to the mechanical properties of the substrate. Boron compounds are used in fertilizer, pharmaceutical, cleaning, nuclear, steel, ceramics, and space industry [4-6]. Boron is one of many commercially important minerals and compounds. It is used as slag builder, alloy element, and surface hardener. Many borides and boron carbides are formed in steels depending on the alloying element. Borides are $\mathrm{FeB}$ and $\mathrm{Fe}_{2} \mathrm{~B}$ compounds. High carbon steel and cast iron boron carbide phases are formed. By boriding to other surface hardening processes one obtains very hard surface (about $2100 \mathrm{HV}$ ), low coefficient of friction resistance to some acid, base, and high temperature oxidation [7].

In the process of diffusing boron to the steel surface, single-phase iron boride $\left(\mathrm{Fe}_{2} \mathrm{~B}\right)$ layer is obtained. A large effect can be achieved with boron atoms between austenite grain boundaries. The boronizing treatment can be realised in a medium together with other additions in solid, liquid, or gaseous form. Recently plasma boron and ion implantation boron method are also used

*corresponding author; e-mail: a.kaouka@lagh-univ.dz in boronizing. A hard ceramic layer can be formed on the material surface by boring. For example, if applied to $\mathrm{Fe}$ surface, this layer is $\mathrm{FeB}$ and $\mathrm{Fe}_{2} \mathrm{~B}$ layer [8-10].

Single phase $\mathrm{Fe}_{2} \mathrm{~B}$ (iron two boride) layer on steel surface it intended. Boronized surfaces have low friction coefficient and high wear resistance. The material retains its hardness and tribological properties at high temperatures. The boronizing process and the resulting layer thickness are also related to the temperature and time of the process. Boriding is widely applied to components, with applications in many industrial sectors such as manufacturing, transport, machinery, and chemical. This process improves the mechanical, tribological, and corrosion properties of the surface. As a result, surfaces of boronized irons and steels have high hardness, excellent wear resistance, good corrosion properties, and strong chemical stability [11-13].

In the literature, there are many boriding applications on several kind of steels [14-18]. All steels are mainly iron alloys. The other constituents of the alloy determine the other structural properties of stainless steel. However, there are a few studies about titanium alloy boride $[19,20]$.

Titanium and its alloys are nowadays common materials in the fields of aeronautics, aerospace, chemical industry, and in the medical field. Titanium alloys have played a key role in improving the performance of gas turbine engines. Compared with nickel base superalloys, these alloys have resulted in a substantial reduction in mass. However, these alloys suffer from a limitation of resistance to creep, oxidation, and fire at temperatures above $600^{\circ} \mathrm{C}$. This has led manufacturers to develop, over the last twenty years, new materials that can surpass these limitations. These materials must be lighter than nickel-base superalloys and have about the same mechanical properties and oxidation resistance as superalloys in common use. It seems that the most appropriate materials for this application are intermetallic TiAl-based 
alloys. Due to their corrosion resistance and mechanical strength, titanium alloys have diverse applications such as implants in medicine and dentistry.

In this study, boriding treatment of titanium alloy Ti6Al4V and their characterisation were investigated. Scanning electron microscopy (SEM), optical microscopy, and X-ray diffraction (XRD) were used as characterize boride layers formed on titanium alloy Ti6Al4V. The microstructure of boride layers obtained on the surface of titanium alloy and some mechanical properties such as microhardnesses of borides layers formed were inspected.

\section{Materials and methods}

Boriding treatment was performed in solid medium based of boron carbide $\mathrm{B}_{4} \mathrm{C}$, at 900,950 , and $1050{ }^{\circ} \mathrm{C}$ for 2,4 , and $6 \mathrm{~h}$. The boron coating solution was prepared by the addition of $0.2 \mathrm{M} \mathrm{NaBF}_{4}$ compound used to increase the conductivity of the non-aqueous or aqueous solutions. The principle of quantitative analysis is to relate the measured intensities to the concentration of the element on the tenant account corrective factors. In the case of a very thin binary sample, the phenomena of absorption and fluorescence X-rays can be neglected. The concentration report is linked to the ratio of intensities. For each study area, magnification is chosen so that it can be distinguished from dislocation. In order to minimize the orientation effects, intersections are counted using concentric circles instead of straight lines. The calculation was done using three concentric circles of diameters $1.5,2.5$, and $3.5 \mathrm{~cm}$, respectively, corresponding to the circumferences. The calculation of the density requires knowledge of the thickness of the blade. This is lost by energy.

The discs made of titanium alloy Ti6Al4V, with $1 \mathrm{~cm}$ diameter, were coated with boron. The surfaces of the discs were mechanically polished with 80 grade rough and 300 and 500 grade fine sand papers. The polished surfaces were then washed with bidistilled water and acetone before being inserted. If the polishing was finer than that, it was observed that the elemental boron did not adhere on the surface and dispersed into the solution. The material is cut beforehand with a micro-chainsaw into thin slices of $150-200 \mu \mathrm{m}$ thickness and then mechanically polished with abrasive paper with finer quality (from the paper 800 to the paper 4000) until reaching thicknesses of 50 to $100 \mu \mathrm{m}$. Discs of diameter $3 \mathrm{~mm}$ were then cut by electroerosion and polished.

The X-ray diffractograms were obtained using technique having symmetric geometry with monochromatized radiation. The diffractometer used in this study was a 4 circles diffractometer. The XRD apparatus was Bruker V8 Discover equipped with a copper source $\mathrm{Cu}$ at a wavelength $\left(\mathrm{Cu} K_{\alpha}, \lambda=0.15418 \mathrm{~nm}\right)$. HITACHI SEM was employed also for the characterization of the covered boride layers. The hardness of the layers was measured on the top surfaces of the samples using micro-hardness indenter (Shimadzu HMV-2) with 25 g loads.

\section{Results and discussion}

The microstructures of polished and etched crosssections of the specimens were observed by SEM and energy dispersive X-ray spectroscopy (EDS). Figure 1 schematically illustrates the practical procedure used to estimate the titanium boride layer thicknesses. The thicknesses of $\mathrm{TiB}_{2}$ layer and $\mathrm{TiB}$ whiskers formed on the Ti6Al4V alloy were measured precisely at 6 different equally spaced locations of a SEM micrograph. These measurements were performed on at least three different micrographs throughout cross-section of the sample with about $12 \mathrm{~mm}$ length. Layer thicknesses and the standard deviations were determined by these multiple measurements.

Boriding treatment does not seem to bring any noticeable change in the microstructure. The isothermal maintenance at $900^{\circ} \mathrm{C}$ leads to microstructural change. The extension of the posture does not seem to bring more changes. The changes observed are the formation of new grains in the interior and at the joints of the lamellar islets. The appearance of precipitates within lamellar analysis of the chemical composition by EDS indicate that these precipitates are very rich in $\mathrm{Al}$ and $\mathrm{V}$. Results of microstructural and chemical analyses on treated samples are then compared to the characteristics of the alloy in the raw state of delivery.

The evolution of the microstructure was analysed by XRD, electrons, and by SEM. The XRD results are shown in Fig. 2. Indexing of the XRD pattern of the raw state shows the presence of three intermetallic phases whose characteristics are grouped together. XRD indicates that for any the parameters of postures isotherms (temperature, time), the three phases $\alpha$, and $\mathrm{Ti}_{2} \mathrm{~B}$ are present in $2 \mathrm{~h}$ of treatment.

The lamellar islets have a well-defined morphology and contours. The lamellar $\alpha$ is characterized by flat and continuous interfaces. Images of the alloy maintained a backscatter electron at 900,950 , and $1050{ }^{\circ} \mathrm{C}$ for 2,4 , and $8 \mathrm{~h}$.

SEM and XRD analyses revealed that the microstructural was changed after isothermal postures. These microstructural changes translate and increase with the

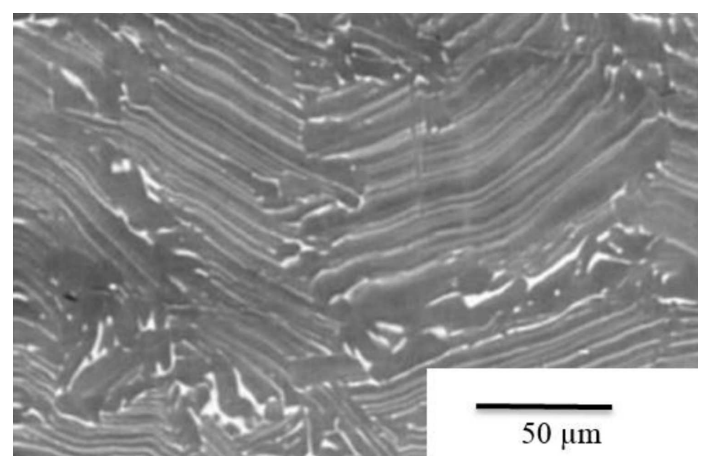

Fig. 1. SEM micrograph of boride Ti6Al4V alloy. 


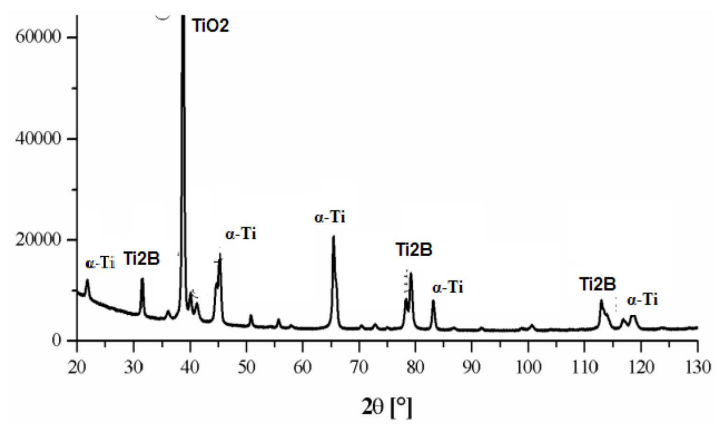

Fig. 2. X-ray diffraction for boride Ti6Al4V alloy.

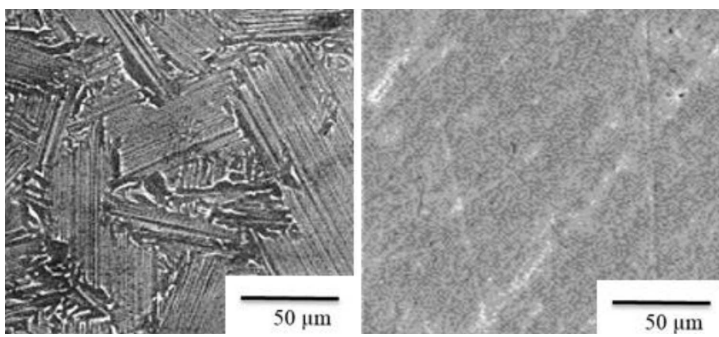

Fig. 3. Microstructure change of boride Ti6Al4V alloy.

percentage of the $\alpha$ phase. The evolution of the microstructure was analyzed by XRD, electrons and by SEM. XRD identified the different phases and determined the atomic mesh parameters and the volume percentages of the phases. Indexing of the XRD pattern of the raw state showed the presence of three intermetallic phases whose characteristics are grouped together. XRD indicates that whatever are the parameters of postures isotherms (temperature, time).

The metallographic study of the cross-section of the samples showed that two distinct titanium borides were formed on the surface of the alloy. The compact and flat $\mathrm{TiB}_{2}$ layer was located near the surface and TiB grew in the form of whisker in the vicinity of titanium matrix. $\mathrm{TiB}_{2}$ layer bonds tightly with $\mathrm{TiB}$ whisker and it becomes slightly thicker with increase in temperature. It has been reported that $\mathrm{TiB}_{2}$ could form first due to lower negativity of the free energy than that of TiB. Ti and $\mathrm{TiB}_{2}$ could further react to form $\mathrm{Ti}_{2} \mathrm{~B}$ as shown in Fig. 3.

XRD patterns of Ti6Al4V samples show the presence of phases of boride layers such as $\mathrm{TiB}_{2}$ and $\mathrm{TiB}$ with additional diffraction peaks from titanium substrates. Microstructural findings were confirmed by XRD analysis. $\mathrm{X}$-ray patterns revealed that increase of the temperature caused an increase of the peaks of $\mathrm{TiB}_{2}$ phase and reduction in the $\alpha$-Ti peak. The XRD analysis is in accordance with the results from recent studies [21, 22].

\section{Conclusion}

This work reports the boron diffusion into Ti6Al4V alloy surface that resulted in two layers consisting of an outer monolithic $\mathrm{TiB}_{2}$ top-layer and $\mathrm{TiB}$ after boriding in the temperature range of $900-1050{ }^{\circ} \mathrm{C}$ for $2-8 \mathrm{~h}$. SEM, optical microscopy, and XRD methods were used to characterize boride layers formed on titanium alloy Ti6Al4V. The microstructure of boride layers obtained on the surface of titanium alloy and some mechanical properties such as microhardnesses of borides layers formed were studied. Thus, titanium borides were successfully formed on the Ti6Al4V alloy. SEM micrographs of the borided Ti6Al4V alloy at temperatures of 900,1000 , and $1100{ }^{\circ} \mathrm{C}$ for 2,4 , and $8 \mathrm{~h}$ are presented in this study and the results obtained were compared with the data available in the literature.

\section{References}

[1] A. Matuschka, Boronizing, Heyden Publ., Philadelphia (PA) 1980.

[2] A.K. Sinha, in: ASM Handbook, Vol. 4, Heat Treating, 10th ed., ASM Int., Materials Park (OH) 1991, p. 437.

[3] G. Palombarini, M. Carbucicchio, J. Mater. Sci. Lett. 3, 791 (1984).

[4] J.R. Davis, Surface Hardening of Steels: Understanding the Basics, ASM Int., Materials Park (OH) 2002.

[5] J. Qiu, Y. Ma, J. Lei, Y. Liu, A. Huang, D. Rugg, R. Yang, Metall. Mater. Trans. A 45, 6075 (2014).

[6] S. Hargovind, P. Madindwa Mashinini, Emerg. Mater. Res. 9, 1 (2020).

[7] B. Rajen, Patel, T. Chou, Z. Iqbal, Emerg. Mater. Res. 3, 115 (2014).

[8] H.J. Hunger, G. Trute, Heat Treatm. Met., 21, 31 (1994).

[9] W. Jia, W. Zeng, J. Liu, Y. Zhou, Q. Wang, Mater. Sci. Eng. A 530, 135 (2011).

[10] A. Kaouka, Int. J. Computat. Exp. Sci. Eng. (IJCESEN) 2, 19 (2016).

[11] A. Kaouka, O. Allaoui, M. Keddam, Appl. Mech. Mater. 467, 116 (2014).

[12] S. Taktak, Mater. Des. 28, 1836 (2007).

[13] D. Mao, X. Wang, W. Wang, X. Wei, Surf. Coat. Technol. 207, 190 (2012).

[14] C. Leyens, M. Peters, Titanium and Titanium Alloys, Fundamentals and Applications, Wiley-VCH Press, Weinheim 2003.

[15] H. Bensheng, G. Yuxiao, C. Peng, X. Wanneng, Emerg. Mater. Res. 9, (2019).

[16] G. Kartal, S. Timur, M. Urgen, A. Erdemir, Surf. Coat. Technol. 204, 3935 (2010).

[17] A. Kaouka, K. Benarous, A. Daas, S.A. Tsipas, J. Surf. Sci. Technol. 33, 53 (2017).

[18] F. Li, X. Yi, J. Zhang, Z. Fan, D. Gong, Z. Xi, Acta Metall. Sin. 23, 293 (2010).

[19] H. Ghonem, Int. J. Fatigue 32, 1448 (2010).

[20] M. Alsawat, Z.I. Zaki, T. Altalhi, N.F. Alotaibi, Results Phys. 13, 102292 (2019).

[21] M. Keddam, S. Taktak, Appl. Surf. Sci. 399, 229 (2017).

[22] A. Kaouka, K. Benarous, J. Mater. Res. Technol. 8, 6407 (2019). 